\title{
Trans-Local Livelihoods and Connections -- Embedding a Gender Perspective into Migration Studies
}

Thanh-Dam Truong and Des Gasper

Draft version of the overview paper (pp. 285-302) for a special issue on transnational migration and multi-local livelihoods, that appeared in Gender, Technology and Development, 2008, as vol. 12, no.3, pp. 285-507.

\section{The Social Field of Migration: Conflict and Contention}

This volume examines intersections between gender, state policy, socio-cultural environment, with a focus on micro-interactions that shape the experience of migration in particular ways. It breaks from the convention that treats different social worlds of international migration as mutually exclusive legal categories. Dominant conceptions of migration produce forms of knowledge that fragment the processes of migration into internal, regional and transnational domains, while maintaining a strict analytical distinction between categories of legal and illegal migration. This fragmentation can obliterate dynamics that lie at the interface between the local, regional, and global domains and between the interlocking systems of migration and the embodied practices of control. Migration networks and practices respond to policy shifts as well as to the strategies of recruiters, employers, and migrants themselves. Knowledge about these dynamics is central to an understanding of contemporary transformations, from which more adequate responses to a range of denial of entitlements and rights and social experiences of security may be derived. Critically revisiting theories, concepts, and methodologies used, and their motivating values, can help to identify flaws and expose unjust aspects of dominant knowledge frameworks. 


\section{Neo-liberal and instrumental views of 'inter-national migration'}

The expansion and influence of migration-domestic and international, South-North, North-North, and especially South-South-is nowadays dramatically visible, at both the upper and lower income-tiers of migration. Migration is a global phenomenon that is closely related to broader economic liberalization, including of services. Neo-liberal governance imposes a bifurcated vision of human movement across borders: favourable treatment of trade-related forms of movement and unfavourable control of those who are on the move through precarious means seeking to secure livelihoods and settlement. An entire set questions of different nature - conceptual, explanatory, ethical and policyrelated - around this situation are beginning to be raised and opened up.

Some of the discussion takes an instrumental approach to migration and asks: What are the links between migration and 'development' (in particular, economic growth)? Some other work asks: In what ways and contexts is migration being problematized? Why indeed is migration so intensely problematized at this particular historical juncture? Through what lens is migration viewed and appreciated, and whose interests drive the instrumental migration-development discourses?

Mapping and interpreting the social field of migration has generated a 'battlefield of knowledge,' in which the social construction of migrants and migration plays an important role in guiding policy formation. The language adopted to discuss migration and migration management can create new power structures or reinforce old ones. Different concepts of 'migration,' 'migrants,' 'migrancy', 'security,' and 'wellbeing' carry conflicting meanings, and the relationship between policy and research in migration is riddled with tension over values and interests. Migration policies are often politically driven and the role of research has remained instrumental within a given political agenda, at best, and marginal at worst. Currently the 'international migration' paradigm remains entrenched, treating the nation-state as a territorial container and only grasping activities and interactions that have measurable impact on sending and receiving societies. Heavily biased towards the representation of the migration experiences of 'productive-aged' 
males this approach has also until recently largely left out the experiences of women, children, younger people, and the elderly, who may either be on the move or left behind and affected by the migration movements of others.

A recent galvanizing point for a gendered understanding of migration in policy-making circles is the revelation that women migrants do remit income and therefore it is considered important to monitor how they remit, to whom and for what purpose. The tendency is to emphasise the 'productive' uses of remittances and ways of promoting them and to decry spending on food, shelter, clothing, and education as 'unproductive' (Pessar, 2005) ${ }^{1}$. Correcting male bias by seeing female migrants through the lens of 'production' is still far from offering a complete representation. Unlike inert objects, people move with their social histories, values and relations that embody the wholeness of their being, something that aggregate flows, especially only monetary flows, cannot capture. Giving space for a wo/manist understanding would require exposing the limits of instrumentalist ways of reasoning deeply entrenched in the dominant international migration paradigm. Citing Austin Bradford Hill who reminded researchers that "statistics represent people with the tears wiped off" (1977), de Tona (2006) emphasizes that the tears of migrant people are what we often overlook and fail to understand. ${ }^{2}$

\section{Transnationalism}

Perhaps more than any other issue, contemporary forms and regimes of migration reflect the limitations of nation-state or regional bloc governance, and demonstrate the need for alternative approaches. Individuals and families do not move once-and-for-all, en bloc, from one jurisdiction to another; people, goods, money, ideas and values move to and fro, via boundary-crossing networks of networks. The 'transnational migration paradigm' has

\footnotetext{
${ }^{1}$ Patricia R. Pessar (2005) Women, Gender and International Migration Across and Beyond the Americas: Inequalities and Limited Empowerment. Expert Group Meeting on Inetrnational Migration and Development in Latin America and the Caribbean. Population Division, Department of Economic and Social Affairs. United Nations SecretariatMexico City, 30 November - 2 December 2005.

2 Ronit Lentin and Hassan Bousetta in Conversation With Carla De Tona. ""But What Is Interesting Is the Story of Why and How Migration Happened". Forum: Qualitative Research Social Research Volume 7, No. 3, Art. 13, May 2006, http://www.qualitative-research.net/fqs/
} 
offered multi-sited and contextualised approaches to the analysis of how rights, security, and livelihood are affected and maintained across multiple different locales and what this means to those who migrate.

In the past decade many attempts have been made to open the international migration paradigm to issues of identity, culture and knowledge that underlie the formation of transnational communities. Borrowing the concept from international relations scholars ${ }^{3}$ who re-theorised the relations between nation-states in the light of the influence of transnational corporations piercing through borders, migration studies uses the term transnationalism to refer to the multifaceted and multi-local processes of cross-border migration, people's experiences as migrants in forming communities in host societies while yet maintaining intensive everyday ties with their societies of origin. The transnational approach aims to expose the deceptive binary constructs, such as nationalglobal and local-global, found in dominant discourses on migration. By revealing the growing interdependence between localities, at various geographical scales (villages, townships, regions, nations), the approach shows the usefulness of seeing state and society through new lenses unobstructed by traditional containers of meanings, in order to grasp the full spectrum of social transactions (Smith and Guarnizo, 1998) ${ }^{4}$.

Placing migration studies in the emerging fields of transnational sociology and ethnography leads this body of work studies the trans-local exchange of material and symbolic goods and excavate the deeper existential meanings of 'being' as mobile subjects. Levitt and Schiller (2004) ${ }^{5}$ discerned different foci of investigation: intra- and inter ethnic groups transnational practices; transnational families; and formation of transnational spaces and social structures and the meaning of collective agency. They propose to give more institutional meanings to transnational migration by treating it as

\footnotetext{
${ }^{3}$ Joseph S. Nye, Jr. and Robert O. Keohane (1971) Transnational Relations and World Politics: A Conclusion, International Organization, Vol. 25, No. 3, , pp. 721-748

4 Michael Peter Smith and Luis Eduardo Guarnizo (1998) Transnationalism from Below Comparative Urban and Community Research V6, New Brunswick: Transaction Publishers

${ }^{5}$ Peggy Levitt and Nina Glick Schiller (2004) 'Conceptualizing Simultaneity: A Transnational Perspective on Society’. International Migration Review. Volume 38, Fall: 1002-1039.
} 
social field in which the formation of transmigrants and their communities and the connections between them are influenced by multiple sets of laws and institutions. They also suggest a use of 'society' as a concept that is no longer equated with the boundaries of a single nation-state. Such an approach, in our view, will help to ground transnational connections more firmly in their contextual realities of power.

Embedding practices of migration in social and cultural lives help to bring into focus the complexity of movements in multiple layers and sharpen methodologies to apprehend contemporary migration as part of an ongoing formation of a global structure of social differentiation, which is constitutive of social change under pressures of globalisation. Migrants' identities - an outcome of a context-specific intersection between legal status, gender, race and ethnicity, culture and ideology - shape the transnational spaces through which they exercise relatedness and express their sense of belonging. Just as the status of their identities and social positioning are stratified by power relations so too are the transnational spaces through which they insert their sense of being and belonging. Fragmentation of social ties, nomadic lives and multi-layered identities are fed by the foot-loose behaviour of transnational capital under neo-liberal globalization. The forces of capital prise open and undermine social protection systems. Socially committed footloose transmigrants restore protection for kin and communities, through great endurance and stress. Yet the realm of transnational migration does not seem to be the beginning of a global grassroots resistance (Faist, 2004) ${ }^{6}$. In transnational spaces the fluidity of identities may obstruct the kind of consciousness required to overcome social divisions, and hence may displace resistance. The nation-state, its polity and territorial control remain significant barriers to enhancing the deliberative power of transnational migrants with or without a formal identity.

\section{Gender in migration studies}

\footnotetext{
${ }^{6}$ Thomas Faist (2004) 'The transnational turn in migration research: perspectives for the study of politics and polity', in Transnational spaces: disciplinary perspectives, edited by Maja Povrzanovicå Frykman, School of International Migration and Ethnic Relations (IMER), Malmö University.
} 
Feminist scholarship has long interrogated male-biases in neo-liberal governance generally and how it affects migration specifically. This wide-ranging scholarship tries to bring to bear the significance of 'gender', its epistemological and methodological values, into research and interpretations about migration. Besides gender-differentiated patterns of mobility and implications for individuals, groups and society, it shows how gender structures thinking, reasoning and understanding of human movements and the identities of those on the move.

Lately, for example, attention has been drawn to how the social constructs of masculinities and femininities shape migration decisions and experiences. It is increasingly recognized that migration can be an escape from the constraints of rigid socio-sexual norms, including hetero-normative dominance (Pessar, 2005; Pessar and Malher, 2006) ${ }^{7}$. A full understanding of the gendering of transnational migration requires accounting for the social construction of migrants' identities as a multi-facetted process that connects a variety of domains in social lives - sexuality, gender, work, home maintenance and child care, institutional life, violence and resistance. Such processes are also embedded in the material inequality derived from racial and legal status.

Research on gender in migration systems has exposed the emotional and social as well as economic values of female niches of migration - such as domestic and care work, commercial sex work, or cross-cultural family formation (Truong, 1996; Kojima, 2001; Ehrenreich and Hochschild 2003) ${ }^{8}$. In particular the focus on the care sector has exposed the chains of negative externalities by which an enhancement of care provision through

\footnotetext{
${ }^{7}$ Patricia Pessar and Sarah J. Mahler (2006) Gender Matters: Ethnographers Bring gender from the periphery to the Core of Migration Studies. International Migration Review, VOL 40 (1) pages $27-63$.

8 Thanh-Dam Truong (1996) Gender, international migration and social reproduction: implications for theory, policy, research and networking. Asian and Pacific Migration Journal, 1996; 5(1): 27-52.

Yu Kojima (2001) 'In the business of cultural reproduction Theoretical implications of the mailorder bride phenomenon'. Women's Studies International Forum Volume 24, Issue 2, MarchApril 2001, Pages 199-210

B Ehrenreich, AR Hochschild (2003) Global Woman: Nannies, Maids, and Sex Workers in the New Economy. Metropolitan Books
} 
labour import in some country can lead to the denial of the entitlement to care of others who stay behind (Parreñas, 2001) ${ }^{9}$. Analysis of gender dynamics in the socio-cultural contexts of migration decisions further shows how state ideology and policy can shape the social environment in which networks operate and form distinctive spatial arrangements and corridors of movements (Tyner, 2000; Oishi, 2005) ${ }^{10}$. Integrating macro, meso and micro perspectives, some authors made visible that rationality of choice is not only plural but also gendered and not all choices can be evaluated in pure economic terms (Piper 2004 ${ }^{11}$, Piper and Roces; Pessar and Mahler 2006). The entries of women and marginalized groups into circuits of mobility take place in a series of unequal points of social, economic and national hierarchies; power dynamics in coping and resisting create a continuum between rational agency and victimhood (Kojima, 2007) ${ }^{12}$.

In sum, embedding gender in migration studies requires methods to investigate the points of intersection between different areas: 1) gender as a reality that permeates social lives, including the daily maintenance of people and resources management; 2) labour as human creativity (and its gendered dimensions) mediated and affected by technological changes, 3) migration as a gendered history of human connections - often set in kinships and family systems, social identities and production relations - can be shaped by demography, socio-economic changes or conflict and war. With the growing integration of local, and national economies into regional and global activities, the approach of embedding gender in migration must also be anchored in situated contexts of

${ }^{9}$ Parreñas, Rhacel. (2001). Servants of Globalization: Women, Migration, and Domestic Work. Stanford, CA: Stanford University Press.

${ }^{10}$ James A. Tyner (2000) 'Global Cities and Circuits of Global Labor: The Case of Manila, Philippines'. The Professional Geographer, Volume 52, Issue 1 February 2000, pages 61 - 74

Nana Oishi. (2005) Women in Motion: Globalization, State Policies, and Labor Migration in Asia. Stanford, CA: Stanford University Press.

${ }^{11}$ Nicola Piper (2004) 'Gender and Migration Policies in Southeast and East Asia: Legal Protection and Socio-cultural Empowerment of Unskilled Migrant Women'. Singapore Journal of Tropical Geography. 25 (2): 216-231

Nicola Piper and Mina Roces Eds. (2003) Wife or Worker?: Asian Women and Migration, Lanham MD: Rowman \& Littlefield Publishers, Inc.

${ }^{12}$ Yu Kojima (2007) Women in The Trafficking-Migration Continuum: From the perspective of Human Rights and social Justice. Shaker Publishing. Maastricht. 
transnationalism to reveal the growing interdependence between localities in different geographical scales and their particularities. Such an approach must discern ethical issues connected with human security at different sites, levels and scales. Understanding transnational migration as a gendered reality intersected with many other social categories requires examination of the nature of these biases in social organizations and how they are exercised in daily lives. Exposing the racialized, gendered and abject constructs of migration in discourses that bear many biases derived from particular conceptions of nation-state can contribute to deeper understanding of, and more adequate responses to, the human experience of migration.

\section{Gender analysis of transnational migration: Aspects of local-global interactions}

What changes take place when migrants (male or female) are away and also when they return? Within a transnational household or network, what happens to gender relations within the household? Do remittances reshape gender relations? What are the gendered obligations and uses of remittances? Does it matter if the people involved in these transactions are male or female? How do different generations view migration and how are they affected? And how are intergenerational relations and concerns affected? Do gender matter in the practices of identity and have bearings on migrants' agency, their engagement with institutions (formal and informal) and their own conception of wellbeing in the transnational space they inhabit?

Analysis of multi-local livelihoods allows a better understanding of the dynamics of migration, the roles of social networks and actors, intra-household level interactions, and the role of remittances. It also helps bring attention to the interrelation between the structural forces that undermine local means of livelihood and the semi-forced or voluntary movements of humans toward other livelihood options; and to questions of identity formation, autonomy and rights claims in each setting. Studying migration as 'transnationalism from below' also reveals the formation of a 'migration culture' or the representation of the experience of being migrants in the symbolic order of those who are on the move or seeking an opportunity to move, particularly among young people. 
Looking at migration from a multi-local point of view has significant policy and research implications, as it fundamentally challenges the binary construct of local-global and the detached understanding of aggregate flows that dominate the migration policy literature. Indeed it is problematic in many cases to draw a clear line between different types of migration: internal or cross-border. Processes of re-configuration and re-scaling of forms of territorial organisation (such as the former Soviet Union, the ongoing expansion of the European Union and the formation of regional blocs in other continents) involves an evolution of territorial identities for which corresponding subjectively coherent identities have not emerged. Borders in mind are difficult to tear down (Struver, 2004), ${ }^{13}$ although moving back and forth between them can be a matter of daily lives rooted in long histories of cooperation and coexistence between border communities. Redrawing formal borders pose a significant challenge on how politics and policy should be organised spatially.

\section{The papers}

Jeevan Raj Sharma's paper sets the stage, by helping to clarify and query the assumptions behind dominant representations of migration, in this case from Nepal to India and back. The paper provides a critique of authoritative development discourses that consider male labour migration as essentially problematic. Drawing on ethnographic fieldwork at multiple sites, including a journey with a group of Nepali men from the hills travelling to the Indian city of Mumbai, it presents evidence that this form of migration is considered not a problem but a normal part of people's formation and livelihood. Many see migration to work in India as an escape from a difficult socio-economic, cultural and familial situation and an opportunity for young men to experience a distant place, experiment with the pleasures and possibilities of consumption, earn and remit money home to fulfil their obligations as responsible men, and hope for upward socio-economic mobility of their households. The paper offers a critique of the conventional discourses for failing to comprehend the socio-cultural meanings associated with this migration, and

\footnotetext{
${ }^{13}$ Struver, A (2004). 'Everyone Creates One's Own Borders': The Dutch-German Borderland as Representation. Geopolitics, Volume 9, Number 3, Autumn 2004 , pp. 627-648
} 
viewing 'migration' and 'migrants' as aberrant irrespective of how people themselves evaluate and categorize it. One might extend his argument to say that while the conventional discourses view migration as potentially bringing various economic gains, given the severe pressures on livelihoods in the hills, they presume that out-migration would cease if not driven by those pressures; whereas Sharma's findings show that this is unlikely to be the case. His paper illustrates how ethnographic research can support critical engagement with policies by surfacing and interrogating their assumptions.

Susan Thieme's paper on migration in and from the Central Asian nation of Kyrgyzstan provides an overview of many of the empirical issues that are examined individually in further detail in other papers. An estimated $20 \%$ of the population is outside the country. She examines families which are spread over space and/or time across a series of locations, and deals with the meanings of multi-locality in a situation where international border control has only recently been instituted, and where female migration is becoming more acceptable and practiced. It became more necessary too in the phase of post-Soviet economic decline, with women more likely to lose their jobs than men, and with the withdrawal of many forms of state support to families. Thieme studied migrants in several different destinations, in Kyrgyzstan, Kazakhstan and Russia, and examines how the motivations and opportunity structures reflect power imbalances related to gender, age, ethnicity, and class. Multi-localities are linked and managed via remittances, which have implications for power relations. Although these migration processes make both women and men vulnerable, women face particular forms of vulnerability that intersect with one another. Middle-aged migrating women experience a devaluation of their education and struggle to handle the multiple roles and expectations of being breadwinner, mother, wife and daughter-in-law, supporting the older and young generations left behind. The youngest generation, born during this transitional period, faces its own challenges of trying to take advantage of economic liberalisation. Thieme provides an insight into the perceptions and experiences of migration and its consequences for the different generations. 
Magali Chelpi-den Hamer and Valentina Mazzucato focus on the different functions played by support networks in the settlement phase of African migrants' migration process once in the Netherlands. What type(s) of support networks, formal and informal, do African newcomers rely on, under which circumstances, and for how long? What is the scope of support offered to them, and is it to be taken for granted? What alternatives are there for those who are left out of the loop? Support groups are seen as having three main functions: (a) providing migrants with the services they lack; (b) helping them to liaise with Dutch institutions; and (c) facilitating contacts. Support was usually timely, allocated 'according to means,' and given in response to a specific need and for a limited period of time. Given that support groups have limited resources and a relatively small scope of action, they usually could not commit to providing long-term assistance. The paper shows how the burden of unwanted migration is yet being shifted from state to non-state actors. A netherworld has emerged of people without legal rights who do many of the low-status low-paid jobs in the North, and are assisted to some extent when in difficulty not by a withdrawing State but by NGOs with very limited capacity, informal networks and some charitable individuals.

Nguyen Thi Hai Yen's paper, co-authored with Thanh-Dam Truong and Bernadette P. Resurreccion, discusses the social construction of identities in transnational migration as experienced by a community of Vietnamese undocumented service workers in Bangkok. Being of rural origin, undocumented and on a sequential and circular trajectory without a definite time frame, these migrant workers are set apart from the larger and more established overseas Vietnamese community and more recent knowledge workers. Members of the overseas community are active however in recruiting and employing them. The transmigrant workers form their own community, to ensure mutual protection and support. Conflating femininity with ethno-marking lends legitimacy to the control over transmigrant women as workers and their identity as Vietnamese. Identified also as homemakers, these women also bear the responsibilities for caring and maintaining the wellbeing of this community. Displacing their resistance and gender conflicts takes place by way of redefining social bonds in the community as kinship relations, thus extending the traditional obligations of women. The paper shows the need to understand social 
differentiation in transnational migrant communities so as to assess issues of incorporation in the host country as well as to assess appropriate modes of assistance for their return to areas of origin in a country undergoing great social transformations.

Paulien Muller's paper explores another 'special case', how Afghan refugees in the Netherlands have coped with and maintained relations with family-members who stayed behind in Afghanistan, Iran and Pakistan. These transnational relations were characterized not only by geographical distance but by an economic, legal and emergent cultural distance and by fundamental differences in terms of safety and security. Embedded in a culture of family and community obligation and solidarity, large-scale remittances to stay-behinds have been a major unidirectional feature. Remittances interact with three other features of the relationship: bringing family members of one remove (parents, children, spouse) to the West; keeping closely in touch; and possible eventual return. The article demonstrates that connection and disconnection can be seen as different moments in a continuum with different mechanisms for relationship maintenance. Generalized reciprocity, cultural expectations and obligations, postponed payment from the past, and postponed payment in the future have prevailed, despite observable imbalances. Sustained large regular remittances have often been at the cost of reducing other types of contact (revisits, and long regular conversations), and in particular they reduce the chances of eventual return.

Following Muller's discussion of the impact of remittances on the remitters, several of the papers examine in detail the impacts on recipients. Referring to West Africa, Marieme Lo remarks that estimates of the aggregate volume of remittances and their contributions to macroeconomic stability and the financing of trade deficits have greatly increased policymaker and researcher interest in remittances. Remittances have shifted over time from being seen as leading to unproductive status symbol investments to investments for place-making, economic revitalisation, and the emergence of a circular hub of import-export and transnational trade. A danger even exists that remittances not only reflect but also in a way permit withdrawal of the state from local social provision, Lo reports. Her paper on Senegal argues that the instrumental paradigm of remittances 
misconstrues or ignores entrenched structural, relational, and gendered dynamics that mediate such transfers and that intersect with power structures that potentially reinforce dependency and economic vulnerability. Using qualitative methods, the paper shows at the micro- level how the gendered pattern of remittances (male to female) has helped women use links with the migrants' diasporic communities to access information that allows them to explore new markets and entrepreneurial opportunities. However, it remains difficult for women to negotiate the social hierarchies surrounding remittances. The 'illegal' status of their migrant husbands does not permit these men to return for temporary visits; the long periods of absence can have a destabilising effect on family relations, unintended negative consequences, and unaccounted social costs. Still, the narratives produced from migrant success stories suggest a picture of wellbeing as a goal to be achieved by spatial relocation and distance. Despite the deadly and dehumanizing trajectories en route to Spain and Italy, these narratives remain powerful in shaping local perceptions and aspirations for migration.

Mallika Pinnawala's paper looks at the impact on their own families of Sri Lankan women's migration to the Gulf States as domestic workers. She uses the idea that a stable household 'back home' needs to link the migrant earner and her approved household 'manager' through effective communication channels. Two new power centres emerge: the daily manager of the household income in Sri Lanka, and the earner of the income, located in the new livelihood space in the Gulf but able to provide detailed instructions and monitoring thanks to the mobile phone. The findings show specific gendered effects on household relations: when the migrant is a woman there is a re-evaluation and adjustment in the domestic power structure, as a person previously in a subordinate position — an 'unskilled' woman from a poorer group — now becomes a principal income provider. Woman migrants consider their remittances to be their own and typically prefer to manage this income by finding a 'proxy manager' rather than rely on their husbands to manage and invest the income - although husbands do in most cases take over some of the absent wife's domestic roles. Many proxy managers are also women, often from the remitter's kinship network: a sister, mother, cousin. A characteristic form of reward is to assist them in turn in finding a job abroad. The gendered livelihood dynamics within 
households bring a qualitative quantitative transformation of operational strategies and household organisation.

Irudaya Rajan and K.C. Zachariah's paper regarding the economic consequences of remittances in Kerala offers a perspective on social differentiation. Migration from Kerala to the Gulf States predominantly involves the Muslim population. Remittances have become enormously significant, with economic, social, and cultural impacts, creating new class structures and an emerging culture of consumerism. Additional migration-related social problems have also emerged, particularly in relation to care drains, which primarily affect children and the elderly. There are signs of the chain effects of migration and class stratification: international migration has provided attractive job opportunities for many people, causing labour shortage in some sectors, which are filled by internal migrants. The political consequences of migration must be carefully examined to counterbalance the economic consequences.

Panitee Suksomboon's paper looks at Thai women migrants who have settled in the Netherlands to form families with Dutch men but who maintain intense contact with Thailand, and at the significance of these cross-border relationships for the socioeconomic transformation of their sender communities. The paper questions economic perspectives that have traditionally looked at the impact of remittances with a 'migrant syndrome' perspective, according to which remittances are assumed to be more likely spent on consumption and unproductive uses, and/or a developmentalist perspective, according to which remittances are supposed to be channelled into productive activities to meet a family's subsistence needs and support economic and community advance. The findings show the importance in addition of a socio-cultural view - migrants' remittances have major socio-cultural impacts and contradictory effects. Remittances contribute to the economic wellbeing of migrants' families and the social development of the local community; they also widen economic disparities and rivalries between migrants and non-migrants. In addition, 'social remittances' - the ideas, identities, and social capital that flow from the in-migration country to the out-migration country - have led to a high value placed on international migration and to a change in marriage choices among non- 
migrants towards a preference for foreign partners. The concept of reverse social remittances is also introduced, referring to the ideas, opinions, and cultural values transmitted to the country of destination, which impact on the lifestyle of the hosts. The preference of a group of Dutch men to marry Thai women is one example of this. The Thai women are more likely to maintain a more deferential and accomodating style than would a Dutch partner, even after years of residence in the Netherlands, partly because their ability to remit to Thailand may depend on remaining within the marriage.

Lastly, a research report by Carmelita Nuqui, also in this issue, looks at a long-term legacy of the large scale migration of Filipina 'entertainers' to Japan and of Filipina brides for Japanese farmers - mixed children, many of whom are not at home in either country. About 8,000 brides enter each year but half these marriages end in divorce. The entertainer trade is larger, with many women trafficked in under false pretences and then in effect forced to enter prostitution. An estimated 150,000 Filipino-Japanese children have been born, mostly now back in the Philippines and no longer in contact with their father. The Japanese state has not interpreted the provision in the Convention on the Rights of the Child concerning the right of each child to acquire a nationality as imposing any obligations upon it. This history gives a new twist to Max Frisch's aphorism, quoted by Nuqui, that "We called for workers and got human beings".

\section{Articulating and embedding a gender perspective}

We have moved from Sharma's re-examination of decisions to migrate and the phase of departure, through to Nuqui's presentation of one of the fundamental legacies of migration - children who possess identities different from any which preceded migration. The papers in this volume show the intricate complexities of migration processes including gender transformations, changing definitions of masculinities and feminities, and new ethnic and cultural identities and legal systems. Many of these aspects remain under- or unexplored. Social forms of human movement are diverse despite significant common features. Muller's paper for example looked at the 'special case' of refugees; but each case is found on examination to be a special case. Each situation reveals specific 
historical circumstances in which gender relations shape migratory processes, and vice versa, how men and women's access to resources affects the relationships with one another. In this light, no simple synthesis is possible; but some common themes are worth noting for further consideration and research. The themes which arise are all central to a gender perspective.

First, all the papers highlight the insufficiency and danger in isolation of purely economic perspectives, for various reasons which we have seen, from Sharma's critique of the 'narrow economic framework' that omits some of the major motives for migration, to the prominence of sexual relations, gender roles, and refashioning of identity in nearly all the papers. For Sharma's migrants, for example, migration to India is a phase of life which is part of growing as a man. Yet the experience threatens their masculinity, and leads many into reliance on prostitutes as a way of reasserting manhood in face of the indignities frequent within migrant life in India, he suggests. Remittance investments may often appear irrational from an economic point of view but have cultural and social significances. We need to explore remittances in a more nuanced way, bearing in mind the multi-dimensionality and cultural specificity of welfare and wellbeing. More generally, migration studies must find the way back to political economy, but now a culturally aware political economy (Jessop and Sum, 2001) and with all the value added from the transnational turn. ${ }^{14}$

Second, we see the centrality of networks and affiliations. Particularly in contexts where state borders are being newly constructed or fortified, migrants depend highly on third parties for help and support. Research in both sending and receiving areas helps to discern new linkages between social networks and a variety of forms of transmission (money, goods, cultural values). Social networks play different roles in different phases of migration and for different categories of migrants. The papers emphasize the need to approach social networks in a more critical way, showing that networks can reinforce as well as transform unequal social hierarchies. Although many networks enable the welfare

${ }^{14}$ Jessop, B., \& Sum, N-L., 2001. Pre-disciplinary and Post-disciplinary Perspectives. New Political Economy, 6(1), 89-101. 
of the migrants, others can exacerbate the vulnerability of certain groups of migrants. The papers reflected on the downside of social networks.

Thirdly, migrants are often sacrificers, who succour others - those whom they support in a country of origin and/or their children who may reap the fruits of their efforts in the country of arrival. Migrants can suffer low status in both countries - Muller's Afghan refugees in the Netherlands could be called 'dogheads' when they revisited Afghanistan, both envied and held in contempt. Families in origin countries seem often to pose great demands (explicitly or as perceived by the migrants), as seen in Sukromboon's case study and her reference to parallel research on Thai migrant women in Germany. Those who would not be able to spend lavishly when revisiting hesitate to make the trip, reports Sukromboon. Some others borrow heavily and/or enter into marital conflict as a result of their expenditures. Amongst Lo's Senegalese migrants, some eventually feel treated by others just as moneybags to be squeezed. One who had lost his high-income New York job and had to stop his high monthly remittances, discovered 'who really cares about you as a human being, and who is only interested in your money'. But migration feeds on, and further feeds, illusions; and generates cycles of attempting to live up to them. To maintain face, migrants must reproduce the image of having entered the land of streets paved with gold, thus fanning further demands upon them, increased interest in foreign spouses, for example, and further migration. To expound instead upon difficulties of migrant life could be humiliating.

Sacrifice means service despite personal loss. So, fourthly, strong felt responsibilities for family, and also for local communities and peer groups, are another recurrent theme, and a strong motive behind present day migration. The responsibility for family is part of core identity; " if you don't do that, you're nobody" says one of Muller's interviewees. In some cases - including those discussed by Pinnawala and Thieme-such feelings of responsibility appeared particularly strong amongst women migrants. Feelings of solidarity, or their absence, critically influence migrants' trajectories in other ways too. They importantly affect the nature and strength of the networks on which they rely. Hamer and Mazzucato found that those who assist new migrants in the Netherlands- a 
mixture of some previous migrants, Dutch volunteers, and other helpers-do not expect payback to themselves. Many Africans help other Africans, and without restriction according to nationality, because they were in the same situation earlier; humanitarian individuals and NGOs (including churches) live out their mandate and commitments. The latter group become disappointed though when most new migrants fail to stay in touch and help others: “"People we help ask how they can help back, but in practice they don't do anything and they stop giving news". Helping is not rewarding...'. Solidarity is in danger of declining over time, for other reasons too, as identities evolve and generations change, bringing perhaps lesser affiliation to 'the old country'.

Fifthly, migration inevitably brings changes of identities - we see migration in some cases as a route to manhood or as spawning new identities not found before in either country - and clashes of identities. Muller illustrates such a clash, between the Dutch state's rejection of refugees as representatives of their families who have responsibilities to their adult relatives, and the refugees' perception that "You are always a child. You are always a mother." Migration impacts also of course on social position, not least for women, especially when they are the money-earning migrant, as discussed by Pinnawala and Thieme, for example. Often migrants can be degraded relative to their former position, as in the case of Muller's male Afghan refugees, whose job qualifications lose value in the Netherlands and who lose some male prerogatives. The women refugees were relatively more likely to find new opportunities in what some Afghan men perceive as "a women's society". Migration typically feeds differentiation of social position between families in the sender country, via remittances.

A sixth theme to underline is that the concept of remittances must be broadened to capture flows in ideological and cultural space and their institutional linkages and consequences. Social remittances as distinct from economic remittances have to do with influencing social values, norms, and relationships between people. Multi-local livelihoods affect social relationships, including gender and age relations and intrahousehold interactions, both in the out-migration areas and the receiving areas. Social remittances could well be sometimes have the most far reaching impacts, besides of 
course the creation of children who grow up in new worlds - not only new for them but new in the strict sense of combinations and social locations that have never existed before.

While all of the imaginable outcomes seem possible, and most papers in this collection emphasise the stresses which migration reflects, involves and generates, one paper takes a more celebratory view. Interestingly, this is Sharma's account of out-migration on a large scale from Nepal to India, typically followed by return, a migratory pattern which dates from the $19^{\text {th }}$ century, one which is much longer established than the migrations studied in the other papers.

Perhaps cross-border migration is one of the greatest empirical challenges to the hegemonic political ideology of free market and de-territorialisation which might correspond to some goods and services but not people. Modern state borders contain the imagined political and social order, and often leaves out or suppress significant internal boundaries and subjectivities and the fragmented lives of those on the move. Mediated by political-institutional, economic and socio-cultural structures migration is inevitably a gendered phenomenon as recently recognized. Migration is also set in family and kinship system, work relations and sense of belonging to communities which implies that the notion of wellbeing, issues of rights and entitlements are not uniform but multi-layered: Who is accountable for whom under which circumstances and contexts? Who can lay claims on whom for what type of support? A trans-local perspective can contribute to and enrich the normative debate on understanding of a human-centred security, which begins with people in real lives. People's mobility in an age of globalisation corresponds to the mobility of finance, goods and services. An imagined political and social order that sees only the mobility of things as rationally permissive and the mobility of some people as the opposite, is bound to encounter discord and dissonance. 